\title{
Fruit of sand: complexities of Botswana's veld plant resources
}

\author{
Marena Brinkhurst
}

This manuscript was prepared under the supervision of President Alastair Summerlee in cooperation with the Department of Geography, College of Social and Applied Human Sciences.

\begin{abstract}
Interest in indigenous veld plants across Southern Africa is generating speculation on the potential market value of veld plant products. Researchers and entrepreneurs in Botswana have begun to explore the botanical resources of the Kalahari veld lands. These developments are attractive to the government of Botswana given national goals of rural development and economic diversification. Attention is turning to possible ways to increase supply, as wild gathering is unreliable and appears to be depleting wild stocks. In particular, domestication and cultivation are being considered. Indigenous plants may be able to avoid some technical constraints on agricultural development in Botswana. However, as explored in this interdisciplinary paper, there are several complications for potential cultivation in the Kalahari. The delicate ecosystem, issues of land access and commercialization, interplay with livestock, social effects of cash income and other changes, and concerns over market development and fair trade are issues that could seriously affect cultivation plans and yet are often overlooked in agrodevelopment studies. It is summarized that methods of management that better fit the natural and social context, such as communally managed gathering, should instead be considered when addressing the problem of overexploitation of wild veld plants.
\end{abstract}

$\mathrm{T}$ he Kalahari Desert is not the empty desert of common imagination. More accurately described as savannah or sandveld, it is a region that encompasses complex ecosystems and incredible diversity of wildlife and flora. Alien and harsh to newcomers, this vast area in central southern Africa has long kept its resources hidden. Now, with the discovery of diamonds in the 1960s and the technology of groundwater-accessing boreholes, the lands of the Kalahari are being viewed less as a liability and more as untapped potential. Attention is now turning to new 'gems' of the sands.

Useful botanical resources of the Kalahari ecosystem have been reported to number near a hundred species. Traditionally, wild seeds, fruits, leaves, truffles, and tubers provided a stable food source and, according to research by Smith et al., ${ }^{26}$ made up 60 to 80 percent of traditional rural diets. Modern demands for traditional food and medicinal plants, and modern uses in cosmetic and industrial processes, have inspired research into increasing the market for veld plant products. $^{6}$ Supporters present the cultivation of indigenous veld plants as technically feasible and a boon for rural development and economic diversification. ${ }^{22,21,6,33}$ However, the excitement over a newly marketable resource has glossed over fundamental complications of the unique ecological and social conditions of Botswana's Kalahari region. Cultivation, in the traditional cropping sense, will encounter challenges greater than drought or input costs. It runs counter to the very nature of the Kalahari. Concerns of ecological balance, land privatization, livelihood tradeoffs, and socio-cultural impacts indicate the need for more suitable management plans for Botswana's sandveld botanicals.

\section{FOOD IN THE DESERT}

Botswana does not have a comparative advantage in mainstream crop production. It is a country of $582,000 \mathrm{~km}^{2}$, two-thirds of which is the scrub-covered Kalahari desert, or sandveld. Conditions are arid - in some areas $150 \mathrm{~mm}$ of rainfall signifies a 'wet' year ${ }^{27 \mathrm{~b}}$ - and rainfall is seasonal and highly variable. In the more fertile regions, crops such as sorghum, maize, and some vegetables are grown, but in such small quantities that in recent years Botswana has had to spend approximately $13 \%$ of all annual import expenditures on foodstuffs ${ }^{7}$ and, as shown in Figure1, the gap between food supply and food production is widening. The demand for imported fruits and vegetables, see Figure 2, in particular has skyrocketed.

Crop agriculture is risky in Botswana, largely because yields are very low and conditions are notoriously unpredictable. ${ }^{32,27 b}$ Agriculture, even including the dominant beef industry, contributes only $2.51 \%$ to GDP, compared to $36.5 \%$ by mining, $15.6 \%$ by government and $10.4 \%$ by the banking sector. ${ }^{10}$ Despite the significant rural population approximately half of Botswana's 1.68 million people, according to the 2001 National Census 2001 - crop agriculture is not a primary employer. Instead, the primary rural industries are cattle-ranching and mineral extraction, both export industries with few linkages to the rest of the economy. 


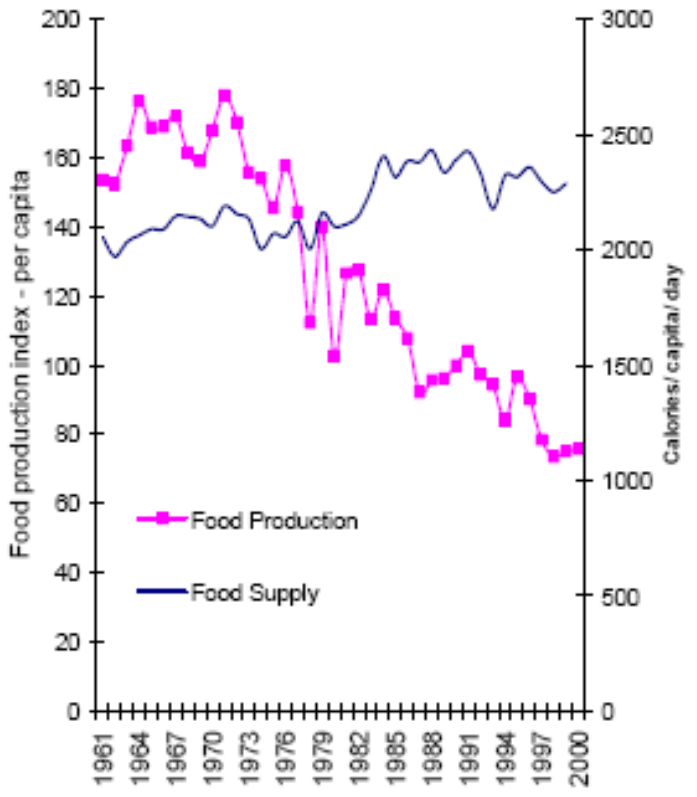

Figure 1: Botswana Food Production and Supply (FAO stats).

Source: Earle, A. 2001.

In one of many efforts to diversify the rural economy, as well as address concerns of rural food security, Botswana is seeking to encourage domestic food production. Despite decades of extension effort and government funds focused on agricultural development, attempts to encourage crop production by government and NGOs in Botswana have met with little success. ${ }^{32}$ Agriculture in Botswana faces several constraints, including its challenging agrogeography, arid climate, and general lack of surface water. It is officially estimated that arable crops will fail once in every three years. ${ }^{30}$ Agricultural activities have largely been limited to cattle ranching and limited rain-fed crops in eastern parts of the country. A lack of familiarity with cropping, limited infrastructure in remote rural areas, and the difficulty of accessing inputs also discourage widespread agriculture.

The western and central Kalahari region stretches into neighbouring Namibia and South Africa. In both countries, initiative has been taken to capture the productive potential of sandveld lands: marketing native botanicals as specialty food and medicinal products. Rooibos tea, made from a native shrub in the Western Cape region of South Africa, is "headed towards becoming the second most commonly consumed beverage tea ingredient in the world after ordinary tea", ${ }^{29}$ with demand over the last ten years growing $742 \%$. Booming demand for another native plant, Hoodia godonii, an appetite-suppressant, is raising concern about overharvesting and is motivating the launch of numerous cultivation programs in Namibia and South Africa. These include efforts by the Hoodia Growers Association of

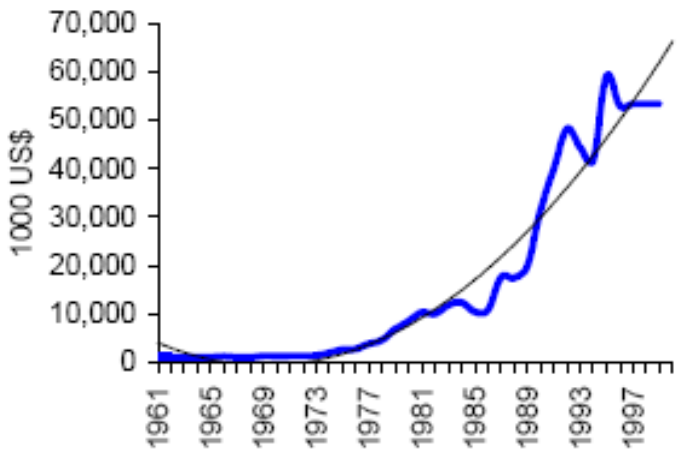

Figure 2: Botswana Fruit and Vegetable Imports, by Value (FAO stats).

Source: Earle, A. 2001.

Namibia (HOGRAN) and other organizations linked to Namibia's Hoodia Commercialization and Poverty Reduction Project. ${ }^{24}$ Namibia and South Africa are converting the region's unique growing conditions into an advantage by developing cultivated native botanicals for international export. Now some development workers in Botswana appear interested in following suit.

\section{Kalahari Plants: Current Situation of Veld Plant Resources}

There exist several species of wild veld plants with marketable qualities in Botswana's Kalahari lands. Many of the main plants with edible, medicinal, or commercial properties that provoke particular interest are highlighted in Table 1, which attempts to summarize findings and points emphasized in NGO and academic research on Kalahari plant species, as well as their traditional and modern usage. Useful wild plants have long been known to the indigenous peoples of the region, collectively referred to as the people of the San. Veld plants were an essential part of the traditional southern African food supply. In the seemingly inhospitable environment, people adapted expert skills at finding food and medicinal uses for the plants around them. Usually described as hunters, the San traditionally depended on a primarily vegetable based diet. ${ }^{28}$ Women were the primary gatherers, responsible for an estimated $70 \%$ of community food supply. ${ }^{28,} 26$ They and traditional healers preserved the knowledge of preparation and usage for about a hundred species of useful plants. ${ }^{26,27 d, 17}$ With a shifting nomadic lifestyle that followed game herds, agrarian techniques were not developed, though work by Stephen suggests that the San did promote certain useful wild plants and were careful to not overharvest any particular area or species. ${ }^{28}$ Thomas also points to extensive management territories between San groups. ${ }^{27 \mathrm{~b}}$ The San remain primary preservers of knowledge of veld plant uses. 
Approximately 50000 San remain in Botswana today. ${ }^{26}$ According to Headland, the traditional lifestyle of the San is being "villagified" as they are absorbed into modern Batswana culture. ${ }^{15}$ Relocations and lost access to lands made many rural San "dependent on ranchers for livelihoods... working for [only] food and water", 28 and a growing dependency on food relief and destitute payments has also been observed. ${ }^{25}$ Reliance upon wild plants has been significant in times of stress. As Ohiokpehai reports, the 1974/75 Rural Incomes Distribution Survey estimated gathering to provide $40 \%$ of rural household income. ${ }^{21}$ Today, reliance is reduced, but still significant. ${ }^{27}$ Social changes and "the modern/settled lifestyle the San have been forced to adopt" $" 17$ have changed the typical diet in rural areas. Generally, interest in traditional roots and vegetables/fruit is being replaced by demand for imported cereals, oils, and produce as it becomes available. Rural food supply is bolstered by Government Food Aid, which provides the preferred modern foods and does not require the extensive effort to gather and prepare wild foods. Many rural San and Batswana work on cattle posts, where food rations are included as part of their wage. ${ }^{27 d}$ Arguably, such changes have bettered the food security of many rural communities, but they have also served to decrease interest in traditional foods.

Even for those plants that are still sought after, a major limit on use of traditional food and medicinal plants is increasingly limited access to them. Ranching and privatization of veld lands have reduced accessible gathering lands. $^{26,28}$ The forced relocations of the San often moved them away from areas rich in wild plants, increasing the difficulty of gathering "even minimal wild resources". 15 Restrictions from commercialization and licensing have further limited which wild plants are used. Recognizing the San's vast store of knowledge is threatened by such challenges, there are ongoing efforts to record and preserve knowledge of veld plants. An NGO, The Letloa LLHRC, has facilitated the production of a database of plants by the Khwe people. Participants to the Letloa project explained that while they would still like to consume wild foods, it is becoming difficult for them to access it:

\section{Today we no longer have our bush food because the government has put us in one place", ${ }^{17}$ "...now it is hard for us to get this food; it doesn't mean that we don't want this food, we are in the government's hand and there is no how we can get this food and eat. We still know the names of these foods our parents used to feed us. ${ }^{17}$}

The Botswana government has a history of changing rights to land held by the San. Lands once treated as vast common lands have been divided up into large cattle ranch holdings, or fenced off as nature reserves. San communities have been forcibly removed from their traditional lands and directed to settle around service centres. ${ }^{27}$ Fundamentally, the shift to a settled lifestyle has decreased the area of land available for wide-ranging gathering expeditions.

\section{New Markets, Increasing Value}

It is only recently that government and decision makers have expressed interest in veld plants. Previously, wild plants carried a prejudice of inferiority and were only consumed in times of extreme need. In urbanizing areas, wild foods were generally viewed as "backward" when contrasted with modern imports. ${ }^{30}$ Now there are indications that general prejudices may be lessening, evidenced by growing availability of wild foods in markets and increased trade in wild plant products. Even in 1983, a survey of South African townships showed "a very substantial demand for traditional wild foods" resulting from disillusionment with "the white man's food"; this, and a fondness for traditional foods seems to be manifesting in urban populations today. Initial assessments of the market for "up-market packaging and presentation of indigenous foods" have been encouraging. ${ }^{30}$

External trade markets appear to be developing as well. A recent market analysis by Bennett singled out a number of plants with particularly promising, or already established, significant market potential. ${ }^{6}$ At a recent FAO conference on non-timber forest products (NTFPs), the Botswana government estimated the value of the NTFP market to be in excess of \$26 million USD - well exceeding the market value for conventional forest exports. ${ }^{30}$ Much of this increasing value springs from growing demand for specialty veld products abroad. The push for "inventories, valuations, and consumption and marketing studies" and identifying further useful plants has begun. ${ }^{30}$ But a gap exists between increasing demand and an informal supply, largely gathered from wild plants on common lands. If the domestic and international market demand for these plant products is sustained, the wild veld is at risk of overexploitation until a sustainable supply emerges.

\section{Signs of Overexploitation}

For several species, increasing harvests combined with existing pressure from intensive cattle grazing is raising concerns about the sustainability of wild plant supplies. Even though many species are quite productive, regeneration time can be lengthy and the ecological systems of the veld can be easily upset. Stress on plant populations is resulting in increasing scarcity of many wild plants. ${ }^{27}$ There appears to be a demand greater than can be sustainably supported by current wild harvesting practices. Developing the full longterm benefits of these new resources depends upon preserving the integrity of the veld ecosystem, while appreciating the complexities of the socio-economic context. As the Botswana NGO 'Veld Products Research' explains, when wild products are in high demand, they are often "exploited unsustainably, until the resource base is exhausted". ${ }^{30}$ Careful planning for resource management is required to ensure "optimal utilization of this resource base 
to uplift the rural poor," rather than the value being captured by middlemen and marketers, and also to protect ecosystems and productivity. ${ }^{30}$ Without these considerations, harvesters risk collapsing a renewable resource and undermining an essential rural food security safety-net.

\section{The Economics of Overharvesting}

In question is the sustainability of wild harvesting practices in the face of rising demand. Analysing the situation of who controls veld resources may help to explain why current gathering patterns are leading to resource depletion. It is the underlying property rights and management rules - official or traditional - that serve to control individualistic reaction to opportunity, which exchanges long term potential benefits for short term gain. Without an institutional framework that encourages management, individuals often logically attempt to capture benefits for themselves.

It has been frequently modelled that in most natural resource situations, the lack of a property rights regime leads to individualistic behaviour and ultimately to inefficient overutilization, a situation popularly referred to as "the tragedy of the commons". ${ }^{14}$ Today, uncontrolled resource access and use is technically referred to as "open access" situations. In the case of Botswana's wild veld plants today, it seems that 'wild harvesting' or 'gathering' are euphemisms for unregulated open-access resource extraction. At one time, such practices did not lead to overharvesting because of limited demand and a geographically shifting pattern of extraction. ${ }^{14}$ Also, it appears there were culturally ingrained rules on harvesting that prevented depletion, and potentially systems of property rights that have now been disrupted. Today, it appears that modern social changes and the concentration of gathering, on lands still accessible and near to settlements, are leading to open-access depletion.

Without some form of management - and this can range from communal to state to private - extraction of valuable resources cannot be controlled. While damage to native Kalahari ecosystems began with intensive cattle ranching, there is certain evidence that the new market value of wild plants is furthering the damage through species-specific overharvesting. ${ }^{30}$ As long as demand is being met through an informal supply based on open access exploitation, negative externalities associated with overharvesting are not being included in the cost of supplying veld products. If suppliers fully accounted for these costs associated with wild harvesting, simple models would predict that a lower quantity would be harvested at equilibrium, as simply illustrated by Figure 3. While increasing scarcity of veld plants will ultimately force supply costs to rise, scarcity indicates exhaustion of the natural resource, limiting renewability.

However, current interest is not focused on these underlying factors. Focus of ongoing investigations is on the constraints imposed on the commercial market by the current supply being limited and erratic. ${ }^{30}$ Attention and development funds are being directed towards stabilizing and increasing supply. In particular, the potential for domestication and cultivation of particularly valuable species is being promoted. ${ }^{30,2,6}$ This possibility is receiving general support as a form of rural development, economic diversification and a way to decrease current extraction pressures and resultant depletion of wild plant resources. Theoretically, a move to cultivation could simultaneously address the underlying absence of resource control measures, as it necessitates private or communal management. However, as shall be seen, these and other presented benefits of cultivation are oversimplified and fail to account for possibly confounding complications.

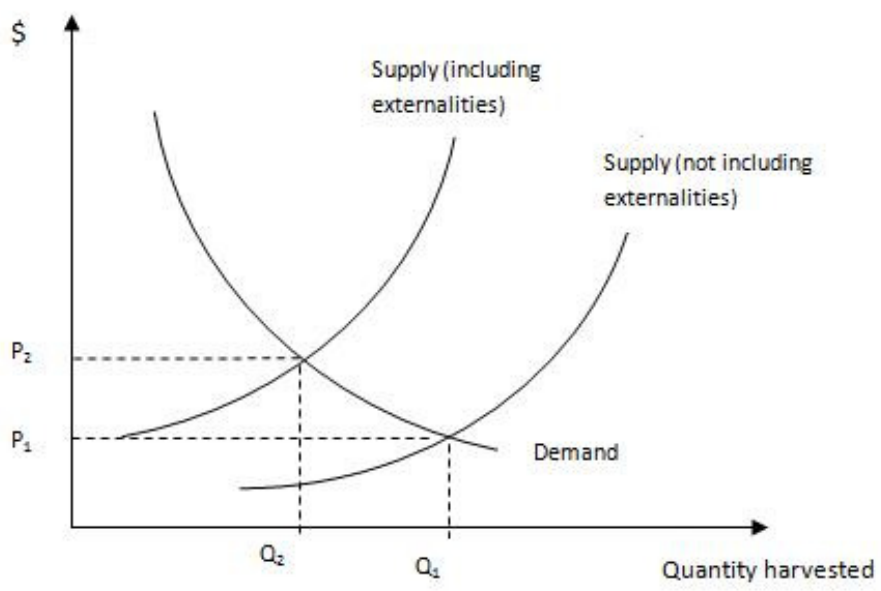

Figure 3: Supply and Demand - the Simplified Effect of not including Negative Externalities

\section{Growing IN SAND: Issues OF Future Veld Cultivation}

\section{Feasibility}

Many native plants are already domesticated and cultivated on a small scale by rural Kalahari households. Research by Arnold et al. reports that twenty-five native veld plants have been identified as having been domesticated and grown for household consumption. ${ }^{27}$ These are primarily those that are a large part of diet, advantageous to cultivate instead of gather, and that are suitable for small household plots, such as cucumbers, melons, herbs, tubers, and some seeds. Tree products and medicinal plants tend to be harvested from the wild. The majority of plants with increasing market potential, identified in Table 1, are not traditionally cultivated, but supporters claim that the potential should be explored. Bennett and others particularly emphasize marula, baobab, and Hoodia gordonii for large market potential. ${ }^{6}$

Increasing the cultivation of native plants is presented as a way to diversify rural livelihoods, while overcoming the constraints limiting conventional crop agriculture. Larger 
scale production of crops like maize and sorghum is limited to areas with greater rainfall and more fertile soils than the Kalahari. The advantage of domesticating and cultivating native plants is that they have adapted to surviving unassisted in natural conditions. Botswana's veld plants are accustomed to dry and fluctuating conditions during their growing season. Through domestication, plants with desirable traits, such as drought hardiness, are bred into cultivars that are suited to cultivation. In the process, yield and quality could be improved. ${ }^{30}$

A changing climate may also make wild plants more important to Botswana. Given predictions of even further decreasing rainfall in the region, ${ }^{23}$ arable crops such as maize and sorghum may no longer be feasible. Trees, shrubs, and roots that can reach deeper water and store it through droughts may be the only plants that can survive changing conditions. Tainton also found that woody species "tolerate utilisation better", ${ }^{31}$ so domesticated tree and shrub cultivars may be particularly desirable in increasingly arid conditions. An example of this is found in South Africa and Zimbabwe, where maize farmers in "marginal areas" have switched to cultivating the tree Tagetes minuta for its essential oil, which was experiencing increased market demand. Farmers prefer the tree because "they are more likely to get a harvest". ${ }^{30}$ Kalahari tree and shrub products could prove similarly advantageous.

However, serious constraints complicate any agricultural development. Previous agro-development projects point to several areas of concern: limitations to land access and agricultural inputs; a lack of experience with cultivating such plants - which could result in variable yields and quality, and therefore profits; the lack of research into domestication; difficulty hiring rural farm labour; a lack of infrastructure for storage, transport, and processing in most rural areas; and difficult market access. ${ }^{32}$ These are all still relevant challenges, but supporters do not see them as insurmountable.

Supporters point to innovative plant cultivars and cultivation techniques as the answer to developing veld products. Alternative approaches to mainstream arable agriculture, such as dryland agroforestry - the inter-planting of tree and herbaceous crops - and Permaculture - a system of 'permanent agriculture' modelling nature's complex and highly productive interwoven plant communities - are also being attempted by some NGOs and researchers in Botswana. ${ }^{27}$ Various projects supported by NGOs and donorcountries are leading extension efforts, attempting to set up co-operatives and other market-access techniques. Dedication of agricultural research and the science of domestication, in combination with innovative cultivation techniques may circumvent the usual constraints to agricultural development in the Kalahari region.

However, even if increasing the supply of veld plants through cultivation would be technically possible, there is a lack of evidence that it is practically so, or even ultimately desirable. It must be recognized that there are greater complexities and implications of increasing cultivation in the Kalahari region, and these must factor into decisions on strategies for increasing veld plant production.

\section{Complications}

Excited by possibilities of veld plant production in neighbouring countries, supporters of wild-plant cultivation in Botswana risk overlooking critical complications specific to the ecological, political, and socio-economic contexts of Botswana's Kalahari region. Consideration should be directed to the variability and delicacy of the ecosystem; patterns of land privatization and commercialization; requirements and impacts of controlling animal movements; issues of market access and fair trade; and cultural impacts. This section will summarize these issues from perspectives not included in recent and ongoing market potential analysis and development plans.

\section{Ecosystem Integrity}

The Kalahari sandveld has been identified as a delicately balanced ecosystem, one finely adapted to the variability and shifting nature of the physical environment. Life in the veld has developed to survive the harsh conditions by creating and stabilizing microclimates. Woodland and more delicate plants grow in the protection of dunes, which are secured by grasses and shrubs, offering protection from often fierce winds. ${ }^{28}$ Naturally, the wild grazers of the veld plants would range over large tracts, moving on after grazing one area. While drought, erosion, and shifting sand dunes are natural components of the physical geography, the ecosystem is a stabilizing force for the vulnerability of these lands. Disruption of soil or water cycles and increasing the extraction of biomass could have unexpected broader consequences on the balance of the ecosystem.

Veld ecosystems are not homogenous. Depending on subtleties of soil structure and moisture content, different species dominate. They can look very different as a result, ranging from forest-like, to shrub-dominated, to savanna-like grasslands as illustrated in the vegetation survey presented in Figure 4. In her review of Botswana's Arable Lands Development Programme, Thompson comments that "the ecology of Botswana is a very fragile one and can easily be upset by misuse". ${ }^{32}$ At the root of its delicacy is the soil. Botswana's soil is primarily "unconsolidated aeolian material", ${ }^{13}$ or sand, without much loam or structure. This makes it highly susceptible to erosion without the grasses and bushes that hold the soil in place. Given winds resulting from anticyclonic weather in the winter ${ }^{28}$ and rainfall that is intense and very rapid when and if it happens, erosion is a serious concern in most of Botswana, where vegetation is disturbed. 


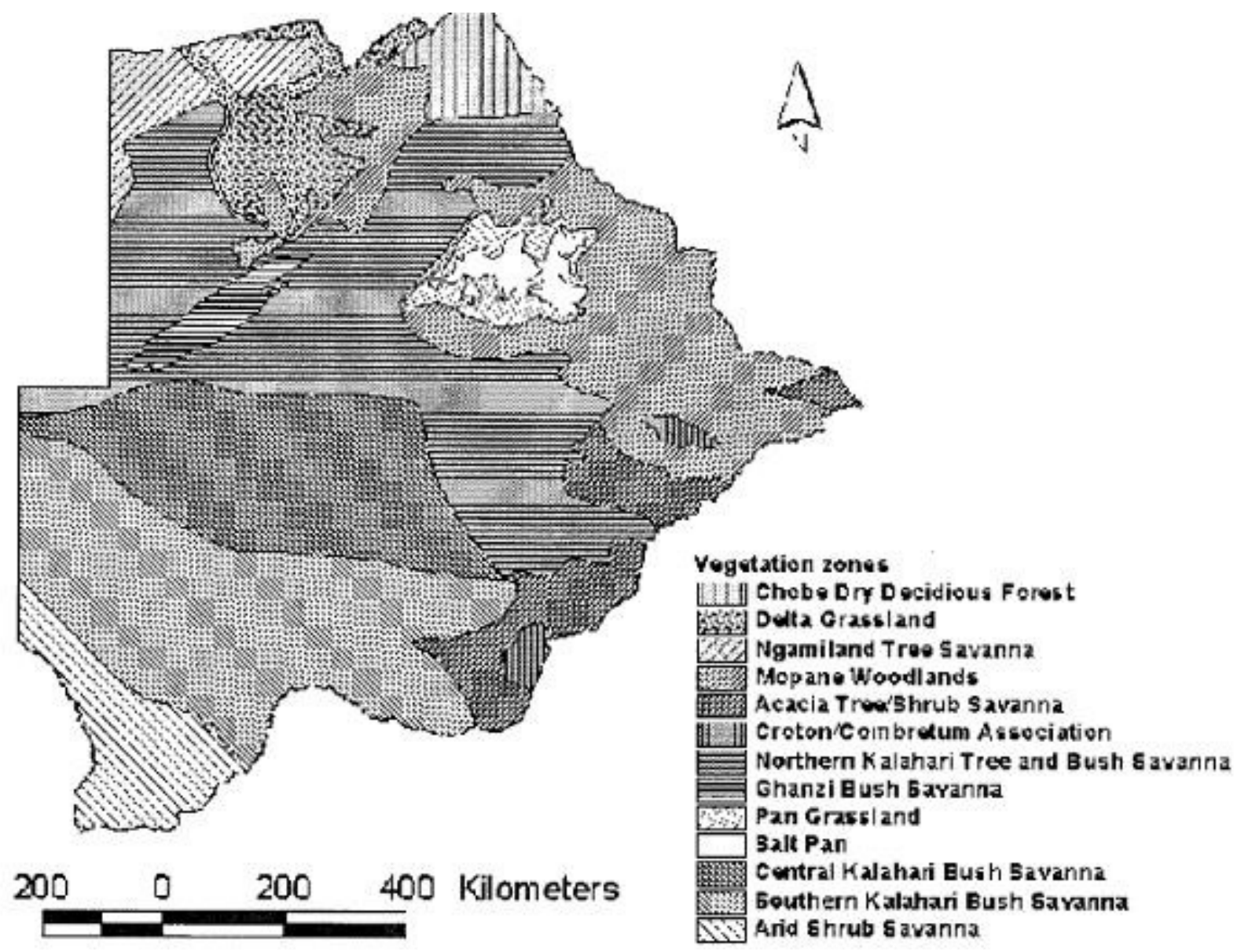

Figure 4: Botswana Vegetation Distribution (1971).

Source: Ringrose, S. et al. 2002

Little scientific research has been done on the impacts of cultivation on soil, water, or ecosystems of Botswana's sandveld. Some experience can be drawn from land use studies in Namibia, which found agricultural land use to negatively impact water resources, quality of land, and biodiversity. ${ }^{4}$ Research by Snyman on soil under cultivation in South Africa shows that disturbance to the natural balance of the ecosystem and soil can rapidly damage soil quality. ${ }^{31 \mathrm{~b}}$ Next to water, soil is the most precious resource to plants in the sandveld. There is an extremely low rate of soil formation $^{31 \mathrm{~b}}$ and what exists is at risk of erosion from flash rains and frequent winds. Soil quality is largely dependent on soil organic matter content, which controls soil structure, water infiltration, water retention capacity and soil fertility, and resilience to erosion. ${ }^{31 \mathrm{~b}}$ While nutrient cycles and soil conditions of the veld have not been widely researched, Snyman found that organic matter content of southern Africa's semi-arid lands to be below $2.5 \%$ of standard cultivated soil and that it is susceptible to dramatic decreases given degradation of vegetation, soil cultivation, and increased soil temperature resulting from decreased cover.

Cultivation extracts vegetation biomass from the ecosystem, depleting scarce nutrients and reducing the amount of organic carbon recycled back into the soil. Replacing lost soil carbon is difficult in southern Africa's sandveld because in arid conditions decomposition is slow and uptake of carbon from decaying material is limited by low soil nitrogen levels. ${ }^{13}$ In these soils, the few nutrients present concentrate near the surface of soils, and so are easily depleted and lost to erosion. ${ }^{31 b, 13}$ Thompson elaborates on the impacts of agriculture on soils:

$$
\begin{aligned}
& \text { Botswana's soil is basically poor, sorely lacking } \\
& \text { phosphate, nitrogen, and other nutrients...Lands } \\
& \text { areas which have long been used are today often } \\
& \text { depleted to the point that farming households cannot } \\
& \text { justify plowing and planting... }
\end{aligned}
$$

While evidently nutrient management is a concern for all of Botswana, it would be especially important in a setting where most nutrients are stored not in the soil, but in the 
cycle of living and decaying biomass, as in the Kalahari. ${ }^{27 \mathrm{~b}}$ Intensifying biomass extraction will act to deplete nutrients, and the ability to artificially replenish fertility of Kalahari soils is questionable. Organic fertilizers, such as manure, are already in high demand and are labour-intensive to spread $^{32}$; Therefore, chemical fertilizers may be required. While transport of chemical inputs into major water systems is less of a concern in the arid Kalahari, there are severe winds that could transport chemical-laden soil if fertilizers or pesticides were employed. Also of concern is the build-up of chemicals and salts in soils, largely due to the effects of evaporation and over application, as seen in regions of 'Green Revolution' India, where soil has been rendered unusable.

If plans for cultivation involve significant trees populations, hydrological systems may also be disrupted. In the Kalahari, water often collects in shallow pans or underground caches. Plants compete to find and store water. There are positive aspects of increasing the woody plants in an area, because trees' root systems penetrate deeper, are stronger, and act to draw up water and nutrients otherwise inaccessible. But encouraging trees will come at the detriment of grasses and herbaceous plants, which compete with trees for water. ${ }^{31,13}$ Increasing leafy vegetation also increases evapotranspiration. High evapotranspiration in veld areas can create moisture deficits, and the greater the moisture withdrawn from the soil, the greater the deficits could become. ${ }^{27 b, 13}$ Predictions of climate change induced drying make this a particular concern.

Another important consideration is the effect of cultivating areas of veld on wildlife. Fences would be required to exclude grazers, and fences have been documented to negatively impact wildlife, by disrupting movements and encroaching upon food and water supplies. ${ }^{34}$ Decreasing wildlife numbers have been blamed on increased fencing of vast areas of land, and increasing human activities in veld areas could further reduce local numbers. Given the increasing value of wildlife tourism, this represents a significant trade-off if cultivation is to take place on large areas of current wilderness.

Given the intricacies of the Kalahari ecosystem, such disturbance through widespread cultivation could impact biodiversity of the habitat. In his discussion of poverty and conservation, Adler, like many, warns that in sub-Saharan Africa "the use of land for agriculture and livestock poses a substantial threat to biodiversity. ${ }^{1}$ Cultivation serves to domesticate areas previously accessible to wildlife, especially if their access is limited to cultivation plots. Even more generally, cultivation gives advantage to certain species by removing competition from undesired species. Given the "delicate balance between the tree and grass components of the vegetation" 31 of the Kalahari, as described by Tainton, engineering the biodiversity of this biome may negatively impact the productivity of the ecosystem, its capacity to withstand harsh conditions, and its ability to regenerate under usage.
The productive capacity of the Kalahari is fundamentally different from typical agroecosystems, in that it has evolved to be in constant flux. Cultivation systems that depend on reliable returns from investment are not suitably flexible. It will be a challenge to promote the necessary investment of scarce resources into production with such high risk. Ecologically, however, the variability of the Kalahari may be its greatest strength, as it develops "ecosystem attributes that generate resilience and mitigate against ecological changes". ${ }^{27 e}$ Plants have evolved to go dormant through droughts and be regenerated by periodic cathartic bush fires. $^{27 \mathrm{~b}}$ Animals have adopted patterns of wide-ranging migration and extensive, shifting grazing. The nomadic practices of the San were based on this balance of impermanence. Production that imposes a system of settled cultivation will have to struggle against this constantly shifting foundation.

\section{Land Access and Commercialization}

The championed poverty-relieving impacts of commercial cultivation in the Kalahari will be complicated by the fact that the majority of rural Kalahari residents do not hold title over land resources. Due to the long history of nomadic land use in the region, private land ownership was historically uncommon, except in certain "freeholder" plots carved out for colonial settlers. ${ }^{27 g, 27}$ Today, since the 1950s advent of borehole technology, private ranches controlling the area serviced by the borehole, legally or otherwise, span much of the rural landscape. In 1975, the central government became more involved in control of land resources. The introduced land classification systems of the Tribal Land Grazing Policy began the ongoing privatization and commercialization of much of what had been communal land. ${ }^{27 b}$ As communal use is concentrated in smaller areas, the capacity for communal lands to support sustainable rural livelihoods is weakened, ${ }^{27 \mathrm{~d}}$ driving many rural dwellers to live and work on the ranches, where they do not control land use decisions.

The power to control management decisions for communal lands is legally ambiguous. Generally, undefined and uncertain land tenure discourages investment in agricultural development. Long term security of ownership is a concern especially with perennial plants, like trees and shrubs, which take longer to yield returns. In the words of Taylor et al.: "Land, or at least tree, tenure is essential if tree crops are to be managed sustainably". ${ }^{30}$ The importance of ownership, or at least management control, over the resource is paramount if people are to be willing to make the significant investment of effort and short-term sacrifice needed for sustainable management. Twyman gives an example of a NGO-led project in East Hanahai, where a group applied for rights to a plot of land for them to grow crops. $^{27 \mathrm{~g}}$ Investment of scarce labour into the project has been limited by the persistent anxiety over the long-term security of the granted rights, in part because of the distorting involvement of the NGO, but also because of the long history 
of losing land rights to the powerful. Rural residents seeking defined private land rights face significant challenges, and it may be long process to build trust in the stability of legal property rights. ${ }^{27 g}$ Until residents feel they have control over their lands, risky investments into cultivation will not be easily adopted in areas where lifestyles are unstable and struggling for simple subsistence. If cultivation is effectively promoted solely to those private landowners already secure in their rights, inequality in wealth generation would be likely. If cultivation is promoted as communal projects, such as with the NGO project mentioned, there are still concerns over the effects of insecure land tenure.

Securing rights through privatization may not improve the situation. Perceived overgrazing and degradation of communal lands have been used to justify the further fragmentation of communal lands into private properties. To be commercially viable, these have tended to be large ranch areas and are rarely granted to the poor rural residents. This has been widely seen as further worsening the wealth divide and intensifying the pressure on remaining communal lands. ${ }^{26,9,27}$ Given ongoing contention over land reform and privatization of common lands attempts to further establish private land rights for cultivation areas may be suspected and resisted. ${ }^{9}$ Previous centralized land use decisions have not improved rural livelihoods for the rural poor. ${ }^{27 g}$ Attempts to promote cultivation may be perceived as further external attempts to control land use, given the underlying complexities of land control and distrust of land reform.

\section{Agricultural Tradeoffs - Cultivation or Cattle?}

It has been remarked that today "the dominant Kalahari mammal is the cow"27b and indeed, commercial ranching has become a major economic activity for all of Botswana, and particularly in the areas unsuitable for crop agriculture. Cattle have been grazed in the region for thousands of years, ${ }^{27 \mathrm{c}}$ but with boreholes they have become a permanent part of the landscape. The profitable Beef Protocol agreement with the EU has greatly propelled the industry. By day, cattle can be seen ranging at will across the landscape virtually everywhere; they are only enclosed in kraals at night, for their safety. These free-ranging livestock populations in rural areas add another concern for cultivation projects.

If cultivated plots contain species vulnerable to grazing, investment in fences will be required. This could represent significant costs if the areas to be cultivated are extensive. Grazing land, especially near to settlements, is heavily used. Grazing and cultivation could possibly be made compatible in creative mixed-use systems, as tree and shrub species have been found to coexist well with grazing pressures. ${ }^{27}$ Otherwise, cultivation will mean there will have to be land excluded from the available grazing area. It is unclear if there is an effective local institutional framework to deal with such land use contests. To maintain feasibility, it will be important to have land use arrangements be cooperative. In particular, water access may be a deciding control factor, as water supply for possible irrigation is largely limited to ranch boreholes, under the control of cattle ranchers.

There traditionally has been some conflict between users of wild plant resources and cattle, as both often centre on available water. Even in the Wildlife Management Areas, set aside to preserve traditional livelihoods and conserve natural areas, livestock have been allowed to encroach. It seems there is a difficult decision to be made between promoting "conservation of the wildlife and veld food resources...and the provision of meat and milk from domestic stock". ${ }^{27 \mathrm{~d}}$ Given the variability of and decreasing access to wild resources, cattle are often given preference. While there is not much research available, evidence seems to suggest that wild plant loss coincides with increased livestock numbers. ${ }^{27, e}$

Power leans towards cattle interests. Culturally, cattle are valued very highly. In most communities, status is still greatly affected by cattle ownership. Research by Twyman indicated that the "rearing of cattle is universally acclaimed ...to be the most important livelihood opportunity" ${ }^{127 g}$ in Kalahari settlements given livestock's importance for reliable income and food security. As a result, past attempts to control or reduce livestock grazing to avoid conflicts with wildlife have not been well received. The most dramatic demonstration of the preference for livestock would be the massive network of 'veterinary fences' that have sliced up the migration routes of wildlife and closed their water access, to the detriment of wildlife populations. While, unlike wildlife, cultivation is another form of agricultural production and so might be more readily recognized as economically valuable, if tradeoffs are demanded between cattle or cultivation, cattle interests will be paramount.

The situation again raises issues of equality. According to work by Sporton and Thomas, 7\% of the population owns half the national herd, and $45 \%$ of people own no cattle at all. ${ }^{27}$ Yet given cultural, economic, and political pressures, land use decisions are made to favour ranching. In typical rural areas, cooperation between cultivators and local livestock owners will be necessary to avoid conflict, and consideration of the distribution of power based on cattle interests will be an important factor.

\section{Fair Trade}

Questions of market access and informal trade infrastructure in remote rural areas raise concerns regarding the potential for exploitation of the rural poor. This is not limited to production under cultivation, as it also applies to production through gathering, perhaps even more so.

According to research by Taylor et al., "middlemen" are currently capturing most of the value of wild veld plants:

\footnotetext{
...the poor and marginalized groups do most of the harvesting of Non-Timber Forest Products. They either peddle their wares within the local community
} 
or else sell them to middlemen, who take the products to distant markets where better prices are available. Either way, the harvesters-gatherers invariably receive a pittance while the middlemen make profits. ${ }^{30}$

It is largely the lack of formal markets in remote areas that is limiting the ability of producers to capture value. Constraints of infrastructure contribute to the continuing informality of rural markets, and the erratic and disorganized nature of the current supply of wild plants is preventing the development of a formal market. Middlemen collect scattered harvests into quantities of interest to large buyers, such as industry and exporters. This situation often traps the harvesters into receiving very little of the revenue, a poverty - and powertrap that can make transaction costs of organizing a market continue to be prohibitively high. In its absence, desperation continues to drive individualistic behaviour.

The development of formal commercial markets for veld plants, following in the tradition of traditional crafts, honey, gums, and resins, would increase the amount of value that is returned to the producers. ${ }^{30}$ To improve market access, some organization of producers will be necessary. As seen in the development of the Hoodia Growers' Association of Namibia (HOGRAN), when producers organize into associations and cooperatives, they wield greater influence in decisions impacting them, such as pricing and fair trade, or intellectual property rights. ${ }^{2}$ If the reported tens of thousands of rural people currently involved in Botswana's seasonal harvests of wild foods could organize, not only will they be able to work for fair trading practices, but a collective management scheme for the resources is more likely to emerge.

Producer organizations and improved market access would also open possibilities of pre-market value-added processing in rural areas. Only simple technologies are needed to produce dried and preserved fruit, nut, or oilseed products. $^{30}$ Such rural industries add value to the final marketable product and preserve shelf-life, important if export is to be the final goal. These activities would also provide opportunities for rural employment. Rural peoples, especially women, have the greatest familiarity with processing and preparing wild foods, changing how wild foods are currently sold could allow them to capitalize on their skilled knowledge.

However, while the potential exists, producers are continuing to behave individualistically. There are often high opportunity costs to organizing cooperative behaviour, especially in uprooted and unstable social contexts. Desperation and the open-access situation as previously discussed are not encouraging cooperation. Supply also depends on whether the plant products are made available for commercial sale or if they are instead kept for local consumption, a potential source of conflict between those gathering for the survival of their families and those gathering for cash income. It can be a risky trade-off to exchange foodstuffs for cash in remote areas with limited access to purchasable food, whose prices are often distorted by limited supply. If commercial supply is to increase, revenue from sales must be enough to overcome local food demands.

Even at current prices, informally set by middlemen, large volumes of wild plants are estimated to be leaving remote areas every season. ${ }^{30}$ There is concern that producers do not realize the full value of their product and so do not attempt to demand a fair exchange price. In discussion with NGOs working with the San, it was perceived that the San are viewed as being fundamentally at odds with conventional concepts of trade and the market. Anthropological research suggests the San were not traditionally a trading people. As Stephen explains, "the idea of an equal return or a good bargain does not seem to be ingrained in San culture". ${ }^{28}$ Similarly, Smith et al. found the attitude towards trade was not about fair reciprocation in goods or value, but rather was viewed as a form of social networking; as a San man explained: "we don't trade with things, we trade with people". ${ }^{26}$ However, in modern markets where buyers have no other contact with producers, money-value is the only way to express the trade. The limited cash economy in remote rural areas, as well as the influence of middlemen, can distort perceptions of price and value demanded by producers. Again, it would require organization and access to market information to enable traditional producers to understand the value of their product and seek a fair trade.

Some of the issues around wild plant products are at a level so far removed from the remote rural areas that producers are not aware of them. Remote rural producers are unlikely to be engaged in the debate over intellectual property rights, but this is a legal argument that allowed the organized Hoodia growers in Namibia to avoid exploitation by companies marketing luxury Hoodia dieting products. ${ }^{2}$ Indigenous knowledge of veld plant uses is already being patented and marketed by international companies. ${ }^{2}$ Without similar organization in rural Botswana, there exists real potential for exploitation of rural producers, whether gatherers or cultivators. These questions of access to markets and information have serious repercussions for the effects of veld plant commercialization.

\section{Socio-Cultural Impacts}

The increasing value of wild veld plants presents an exploitable resource for rural communities, especially the San given their knowledge of wild plants. However, the implications are not straightforward, and not all are positive. Questions of equitable distributions of benefits, effects of increased cash flow, implications for rural food security, and commercialization of traditional knowledge are important in evaluating development of a Kalahari veld plant industry.

As indicated in the discussion of access to land, there are clear divisions of wealth in many rural areas of the Kalahari. Distribution of benefits from cultivation will largely depend 
on the models of ownership favoured. If only large private landholders can feasibly cultivate veld plants for commercial sale, there will be many rural inhabitants who will be excluded. Employment opportunities may be possible, but if the experience with the cattle-post system is an indication, such positions of dependency only continue the poverty trap. The rural poor may even be worse off if increased veld plant production decreases the local availability of wild food sources used to supplement meager food wages.

An important consideration with regards to agricultural development in the Kalahari is the nature of labour-sharing. According to research by Twyman, the primary constraint for Kalahari farmers is the availability of labour to prepare land, tend, and harvest crops, as the growing season corresponds to the employment season for the national Labour-Based Drought Relief Programme. ${ }^{27 \mathrm{~g}}$ Therefore, rural inhabitants must decide between allocating their labour to agriculture and subsistence activities or wage-income and government relief. To cope with labour scarcity, cultivators often engage in field-sharing practices, where labourers earn a share of the harvest. With the coming of commercial markets and inputs, such as tractors, some farmers are moving away from traditional field-sharing arrangements. ${ }^{27 \mathrm{~g}}$ Sporton and Thomas claim this is a result of government policy that focuses on conventional ideas of "rationally based individualized peasant production", instead of realizing the importance of field-sharing and "inter-household production", social behaviours that shape how communities function and distribute food and assets. ${ }^{27}$ Already, changes are creating social divides between those who are able to 'modernize' and those still engaged in traditional shared production.

Further commercialization would also impact social treatment of property rights regimes. Research by Solway indicates that in traditional rural communities, 'property' is thought to come from ancestral entitlements, but because everyone in a settlement tends to be closely related by blood or through ties of 'kinship', this effectively makes most resources communal, or at least widely shared. ${ }^{27 \mathrm{~h}}$ Commodification provokes a change to "the private end of the property continuum" and a focusing on a resource's "exchange value" captured by the individual, instead of the more traditional sense of "use value" that is shared communally. ${ }^{27 \mathrm{~h}}$ Therefore, even without land reform and official privatization policies, increasing commercialization will cause social change with respect to perceptions of property. This would have serious implications for those in the rural population who do not hold individual title to productive resources, many of whom are widowed or members of a female-headed household. ${ }^{27 \mathrm{~h}}$

Related to the concept of "exchange value" and "use value" with regards to private property, the concept of money is also not a traditional part of rural culture. In the context where the sharing of useful resources contributed to social standing, cash income - or pure "exchange value" - is not the primary decider of social standing. ${ }^{27 \mathrm{~h}}$ It is an individualized form of property, and does not assimilate easily into a system of communal ownership. This could contribute to the prevalence of alcohol abuse associated with areas where cash income makes it accessible, as was commented upon in interviews with some NGO workers in the San settlement at D'kar. Combining substance addiction with a dearth of other purchasable goods in remote areas, cash flow into rural communities can have serious negative effects.

The lack of infrastructure and market access in remote areas also results in concerns over the food security implications of producing wild plants for commercial sale rather than local consumption. Veld plants are an important safety net for the rural poor to turn to in times of drought and food shortages. Domestication and cultivation could further increase the food security of rural areas, ${ }^{21}$ but if there is market pressure to sell them, producers might trade foodstuffs for cash income. Then food security would depend on purchasing from other local producers or imported goods, the nutritional quality of which, compared to fresh plant products, is sometimes questionable. Also, production depends on demand - if there is export demand for plants without much nutritional benefit, areas could see increased production but without any improvements to local food availability. Perkins et al. offer a cautionary note to assuming wealth generation will compensate for changes in local food availability, since the emphasized income generation from commercializing veld products assumes a degree of profitability, "whose potential over much of the Kalahari must be stated to be limited."27d Claims that cultivation and commercialization will improve rural food security must be carefully examined.

In addition to being an important supplementary food source, wild veld plants are also culturally significant. The knowledge of Kalahari food plants has been a treasure of the San people for thousands of years, enabling them to live in their remote lands and maintain a separate cultural identity. Twyman comments on how mechanisms of resource management, "complex sets of rights and relationships" $27 \mathrm{~g}$ governing the gathering and use of plants, are foundational to social structure. As documented by the Letloa project, many plants are given cultural importance by having their use only granted to healers, or by associating maturity and adulthood with consumption of certain plant products. ${ }^{17}$ The medicinal significance of veld plants is still felt incredibly strongly in traditional communities, where individuals prefer to be treated with plant remedies administered by traditional healers than seek medical aid from mobile clinics.

Even where no longer essential to survival, gathering and using wild plants carries cultural significance. The symbolic preservation of traditional knowledge connects people to their cultural past and continues to association of value with traditional activities. ${ }^{27 g}$ Carrying on this expertise gives rural settlement inhabitants a sense of pride, something often 
lacking where an ethos of dependency and lack of control is often dominate. Commercializing this knowledge, especially without recognition or compensation, is potentially a threat to the cultural significance of veld plants. Appropriation of traditional knowledge and culture has wide social implications, as evidenced in the many controversies over indigenous knowledge and intellectual property rights. ${ }^{16}$

Fundamentally, the question of cultivation is a question of empowerment and resource control. Commercial cultivation of veld plants may be welcomed by rural communities, who can assess the local appropriateness of production techniques and better evaluate the costs and benefits of cultivation and commercial sale better than any centralized or outside programming.

The issue of resource control reaches beyond the specifics of veld production. As Twyman concludes, land rights issues are "far greater than a $200 \mathrm{~m}$ by $200 \mathrm{~m}$ plot near the settlement"; they signify the struggle to remain connected to 'land' as a "vast resource on which to make a living". ${ }^{27 g}$ It is a struggle over self-determination and the control of rural livelihoods, in a context of extensive distortions of power and control over veld resources. The true significance of veld plants and their diverse contributions to rural livelihoods, from drought coping mechanisms and income generators, to essential foodstuffs for rural poor and female headed households, to preservers of traditional customs and social fabric, is impossible to fully account for in centralized economic calculations. Without consideration of the complexities of cultivating veld plants, efforts to commercialize their production, even if guided by goals of equitable, sustainable rural development, run the risk of joining the history of development policies that, in practice, further damage rural livelihoods.

\section{Progress through Tradition: Communally ManAged Gathering}

The wild veld plants of the Kalahari hold great potential as food, medicinal, cosmetic, and industrial products. But they are not a new 'wonder crop' that will solve Botswana's agrodevelopment challenges. The unique natural and social conditions of the Kalahari region complicate the constraints upon cultivation and amplify environmental and cultural impacts. As increasing market value of veld plants places greater strain on wild populations, Botswana must encourage sustainable management of veld plants, but cultivation is unlikely to be the solution.

Answers may lie in the traditions developed by the Kalahari peoples over thousands of years. The modern system of cattle production is learning from tradition. Its system of fixed, fenced ranches led to disasters in times of fodder-destroying drought. The response, amongst those who remembered the traditional pastoral techniques, was to lower the fences and herd the animals to less-affected areas. ${ }^{27}$ These ranches saw the fewest losses.
Tradition can also guide the response to veld plant management. Continuation of open-access resource extraction could destroy a potentially sustainable resource for the people of the Kalahari. Perhaps it is time to return to traditions of shifting, communally managed gathering for inspiration. Cultivation and wild harvesting are not mutually exclusive. There could well be interactions and gradients between the two scenarios. Producer cooperatives and systems of communally managed gathering, inspired by common-property resource management regimes around the world, ${ }^{3}$ present models of communities successfully following locally-suitable management through communally structured cooperation. Such approaches require a motivated and empowered community, however. For those in situations of extreme poverty, accepting responsibilities for ecosystem management and the accompanying short-term sacrifices for long-term investments will be difficult. But continuing the tradition of external control and disconnecting communities from their natural resource base will not address these situations at the root. Control over land and resource use, and so self-determination of rural communities, is the only route to broadly accepted and sustainable long-term management of natural resources, including the valuable wild veld plants of the Kalahari.

Capitalizing on the opportunity presented by veld plants through cultivation may provoke complications greater than those accounted for in typical agricultural impact studies. In the dynamic setting of the Kalahari, no rigid production plans will be suitable. Instead what is required is a combination of flexibility, local responsiveness, and preservation of traditional knowledge to fit the complex ecological, social, and economic contexts of the Kalahari region.

\section{REFERENCES}

1. Adler, J.H. (2002) 'Do Conservation Conventions Conserve?', Chapter 11 in Morris, J. (2002) Sustainable Development: Promoting Progress or Perpetuating Poverty? London: Profile Books.

2. Africa News Network (ANN) http://www.africafront.com/ March 03, 2008: "University of Namibia to domesticate wild bean plant"; August 7, 2008: "Commercialization of hoodia cultivation takes off in Namibia".

3. Agrawal, A. and E. Ostrom (2001) 'Collective Action, Property Rights, and Decentralization in Resource Use in India and Nepal' Politics \& Society, 29(4): 485-514.

4. Ashley, C. (1996) 'Incentives affecting biodiversity conservation and sustainable use: the case of land use options in Namibia' Research Discussion Paper, Number 13 (Windhoek, Namibia: Ministry of Environment and Tourism).

5. Behr, K. (2004) "Vanguerua infausta". Pretoria national Botanical Garden. 
http://www.plantzafrica.com/planttuv/vanguarinfaust.ht m [Jan. 26, 2009].

6. Bennett, B. (2006) 'Foreign Direct Investment in South Africa: How big is Southern Africa's natural product opportunity and what trade issues impede sectoral development?' Pretoria: Regional Trade Facilitation Programme.

7. Botswana Central Statistics Office (2007) "Imports by Principal Commodities". http://www.cso.gov.bw/trade\%20stats\%20imports\&exp orts/Website-Table-upto-June-2007---PrincipalImports.pdf [Jan. 26, 2009].

8. Capenature (2008) "Sandveld Open-Day Encourages More Environmental-Friendly Farming- Rooibos Wants To Go Green". (Press Release). www.capenature.co.za.

9. Cullis, A. and C. Watson (2005) 'Winners and Losers: Privatising the Commons in Botswana' Pastoral Civil Society Programme, International Institute for Environment and Development (IIED): Securing the Commons No.9.

10. (DTI) Department of Trade and Industry, Republic of South Africa (2006) "Botswana Economic Overview" (2000/2001).

http://www.dti.gov.za/econdb/raportt/botswanaOvervie w.html.

11. Earle, A. (2001) 'The Role of Virtual Water in Food Security in Southern Africa' Occasional Paper No. 33. University of London: Water Issues Study Group.

12. FAOstat (2009) Food Balance Sheets. (Botswana) http://faostat.fao.org/site/368/DesktopDefault.aspx?Pag $\mathrm{eID}=368$ [Jan. 26, 2009].

13. Graz, F.P. (2004) 'Structure and Diversity of the Dry Woodland Savanna of Northern Namibia' University of Gottingen (Gottingen).

14. Hardin, G. (1968) 'The Tragedy of the Commons' Science, 162 (3859): 1243 - 1248.

15. Headland, T.N. and D.L. Blood (ed). (2002) 'What Place for Hunter-Gatherers in Millennium Three?' United States of America: SIL International, Publication 38.

16. Krugmann, H., Cole, D., and P. du Plessis (2003)

'Access and benefit-sharing mechanisms for the use of botanical resources in Namibia' DEA Research Discussion Paper, Number 66. Windhoek, Namibia: Ministry of Environment and Tourism.

17. The Letloa LLHRC. (2007) '॥Xom Kyakyare Khwe: Tc'ao Yidji Djaokalloe Kx'ea †'Úî́ \|oe Yidji nu Tcokaelloe Yidji'/'The Kwhe of the Okavango Panhandle: The Use of Veld Plants for Food and Medicine' Shakawe, Botswana: Kuru Family of Organizations.

18. Mshigeni, K.E., Mtango, D., Massele, A., Mgonda, Y., Lyamuya, AE., Elineema, M., and ST. Chang (2005) 'Intriguing biological treasures more precious than gold: the case of tuberous truffles, and immunomodulating Ganoderma mushrooms with potential for HIV/AIDS treatment' Discovery and Innovation 17(3\&4): 105-109.

19. Mojeremane, W. and S.O. Tshwenyane (2004) 'Azanza garckeana: A Valuable Edible Indigenous Fruit Tree of Botswana' Pakistan Journal of Nutrition 3(5): 264-267.

20. Marama Project, University of Copenhagen. "MaramaDevelopment of innovative and Healthful Marama Bean Products". http://www.marama.life.ku.dk/ [Jan. 26, 2009].

21. Ohiokpehai, O. (2003) 'Promoting the Nutritional Goodness of Traditional Food Products' Pakistan Journal of Nutrition 2(4): 267-270.

22. Phytotrade Africa (2007) "Better Products for a Better World" (factsheets). http://www.phytotradeafrica.com [Jan. 26, 2009].

23. Ringrose, S., Et al. (2002) 'Environmental Assessment: Climate- And Human-Induced Woody Vegetation Changes in Botswana and Their Implications for Human Adaptation' Environmental Management 30(1), 98-109.

24. Rural Poverty Reduction Programme (RPRP) (2008) "Hoodia Commercialization and Poverty Reduction Project" Namibia: National Planning Council. http://209.139.209.202/index.php?option=com_content \&view $=$ article\&id=25\&Itemid=17 [Jan. 25, 2009].

25. SEPASAL, Royal Botanic Gardens, Kew (1999) "Survey of Economic Plants for Arid and Semi-Arid Lands (SEPASAL) database". http://www.rbgkew.org.uk/ceb/sepasal/internet/ [Jan. 20, 2009].

26. Smith, A, Malherbe, C., Guenther, M., and P. Berens (2000) The Bushmen of Southern Africa: A Foraging Society in Transition Athens: Ohio University Press.

27. Sporton, D. And D.S.G. Thomas (ed.) (2002) Sustainable Livelihoods in Kalahari Environments: A Contribution to Global Debates Oxford: Oxford University Press. a - Sporton, D. And D.S.G. Thomas (2002) 'Introduction' 1-20. b - Thomas, D.S.G. (2002). 'Sand, Grass, Thorns, and...cattle: The Modern Kalahari Environment' 21-38. c - Sporton, D. and C. Twyman (2002) 'Politics, Policy, and Livelihoods' 39-66. d - Perkins, J.S., Stuart-Hill, G., and Kgabung, B. (2002) 'The Impact of Cattle-Kepping on the Wildlife, Vegetation, and Veld Products' 67-90. e - Dougill, A. (2002). 'Ecological Change in Kalahari Rangelands: Permanent or Reversible?' 91-110. f - Sporton, D. and Thomas, D.S.G. (2002). 'Environmental Change, Entitlements, and Poverty in Kalahari Pastoral Systems' 111-130. g - Twyman, C. (2002). 'Entitled to a Living: Opportunity and Diversity in Wildlife Management Areas' 
h - Solway, J.S. (2002). 'Drought as a Revelatory Crisis Revisited: An Exploration of Shifting Entitlements and Hierarchies' 193-216. i - Sporton, D. and D.S.G. Thomas (2002). 'Local Lessons for Global Problems: Contributions to Global Debates' 217-226.

28. Stephen, D. (1982) 'The San of the Kalahari' Minority Rights Group Report No. 56 London.

29. Swiss Business Hub South Africa (SBHSA) (2007) Pretoria, SA: South Africa Sector Report Food \& Beverages Industry.

30. Taylor F., Mateke, S.M., and Butterworth, K.J. (1998) 'A Holistic Approach to the Domestication and Commercialization of Non-Timber Forest Products' Gabarone, Botswana: Veld Products Research, in Food and Agriculture Organization of the United Nations (1998) FAO Corporate Documents Repository, NonWood Forest Products 9, Domestication and commercialization of non-timber forest products in agroforestry systems' International Conference on Domestication and Commercialization of Non-Timber Forest Product.

31. Tainton, N.M. (ed.) (1999) Veld Management in South Africa Scottsville, SA: University of Natal. a - Tainton, N.M. 'The Savanna Biome' 33-36. b - Snyman, H.A. 'Soil Erosion and Conservation' 355380 .

32. Thompson, C. (1991) Harvests Under Fire: Regional Co-operation for Food Security in Southern Africa London: Zed Books.

33. Tibe, O., Modise, D., and Mogotsi, K. K. (2008) 'Potential for domestication and commercialization of Hoodia and Opuntia species in Botswana' African Journal of Biotechnology 7(9), 1199-1203.

34. Verlinden, A. (1996) 'Human Settlements and Wildlife Distribution in the Southern Kalahari of Botswana' Biological Conservation 82:129-136. 